\title{
Detection of misdiagnosed thyroid dysfunction in early pregnancy: using nonpregnant and pregnancy specific reference intervals
}

\author{
Kumari BA ${ }^{1}$, Vanumu C. $S^{2}$, Divyasai $V^{3}$ \\ ${ }^{1}$ Dr. Bandaru Aruna Kumari, Assistant Professor, Department of Biochemistry, Osmania Medical College, NTR \\ University Of Health Sciences, Hyderabad, Telangana, ${ }^{2}$ Dr. Vanumu Chandra Sekhar, Professor, Research and \\ Development, CMR-CET, Hyderabad, Telangana, ${ }^{3}$ Divyasai Vanumu, $1^{\text {st }}$ year MBBS, Siddhartha Medical College, AP, \\ India.
}

Address for Correspondence: Dr. Bandaru Aruna Kumari, Email: varunakumari@gmail.com

\begin{abstract}
Objective: The objective was to assess the prevalence of misdiagnosed thyroid dysfunction during the first trimester of pregnancy when nonpregnant reference intervals used. Materials and Methods: This study, conducted on 233 pregnant women of age between 18 and 35 years during first trimester. Serum thyroid stimulating hormone (TSH), free thyroxine (FT4), thyroperoxidase antibodies (TPO Ab) analyzed and thyroid disorders were grouped, based on the first trimesterspecific reference intervals and correlated with nonpregnant reference intervals. Results: The overall prevalence of autoimmunity was $12.4 \%$. The prevalence of subclinical hypothyroid $(\mathrm{SCH})$ was significantly higher than euthyroid when first trimester-specific reference intervals used rather than nonpregnant reference intervals. If the nonpregnant reference intervals were applied to our study group, $27.9 \%$ pregnant women with TSH above the first trimester-specific reference intervals would not have been identified and misclassified as euthyroid. $22.7 \%$ would have missed the diagnosis as SCH. 5.2\% with low FT4 levels, among this $3 \%$ and $2.1 \%$ would not have been identified as overt hypothyroid and isolated hypothyroxinemia. The relative risk of autoimmunity was significantly 3.66 times more in SCH than euthyroid, when first trimester-specific reference intervals used. Conclusion: Misdiagnosis of SCH, overt hypothyroid and autoimmune thyroid disorders occurred during the first trimester of pregnancy if nonpregnant reference intervals used. Undiagnosed hypothyroidism in pregnant women may adversely affect their fetuses; therefore the early and appropriate detection of thyroid dysfunction require reliable pregnancy-specific reference intervals of the thyroid hormones.
\end{abstract}

Key words: Euthyroid; free thyroxine (FT4); subclinical hypothyroid; thyroid stimulating hormone (TSH); thyroperoxidase antibodies (TPO-Ab)

\section{Introduction}

Pregnancy may affect the course of thyroid disorders and conversely, thyroid diseases may affect the course of pregnancy. Many pregnant women with thyroid disorder remain asymptomatic, the diagnosis is exclusively biochemical. Thyroid hormone adequacy is crucial for normal fetal neurodevelopment, particularly during the first trimester [1-3]. Pregnancy complications such as spontaneous miscarriage and gestational hypertension, placental abruption and premature delivery are increased with maternal hypothyroidism $[2,4]$. Similarly the presence of antibodies to thyroid

Manuscript received $7^{\text {th }}$ June 2016

Reviewed: $16^{\text {th }}$ June 2016

Author Corrected: $28^{\text {th }}$ June 2016

Accepted for Publication $19^{\text {th }}$ July 2016 peroxidase (TPO-Ab) has been associated with increased risk of miscarriage, preterm birth, failure to conceive with in vitro fertilization, [5] and maternal postpartum thyroiditis [1]. In view of these associations with adverse outcomes, all pregnant women should be screened for thyroid dysfunction to identify those at risk.

Pregnancy produces a series of profound physiologic changes, in turn, complicate the interpretation of maternal thyroid function tests. As a consequence, the United States National Academy of Clinical Biochemistry (NACB) recommends that 'trimesterspecific reference values should be used when reporting 
thyroid test values for pregnant patients [1], utilizing nonpregnant reference values during pregnancy may lead to diagnostic errors. The aim of this study are to decide whether to use the nonpregnant reference intervals or pregnancy-specific reference intervals of thyroid related hormones to determine the thyroid dysfunction during early pregnancy \& to find out the prevalence of thyroid dysfunction and thyroid autoimmunity in pregnant women based on these two different reference intervals.

\section{Materials and Methods}

This study was conducted on 233 pregnant women of age between 18 and 35 years during the first trimester, attended in antenatal OP, Government Maternity Hospital, Hyderabad, India. Two women had hyperthyroidism were excluded from the study. The study approved by the institutional ethical committee of Osmania Medical College, Hyderabad, and informed consent was obtained from all pregnant women. Pregnant women with known thyroid problems and taking medications other than nutritional supplements, $\mathrm{TSH}>10 \mu \mathrm{IU} / \mathrm{L}$, and subclinical hyperthyroidism was excluded from the study. History was taken in detail including the present, past, obstetric, family, and personal history. None of the patients had previously diagnosed thyroid disorder (hypo- or hyperthyroidism). At least $5 \mathrm{~mL}$ of blood was obtained from all the selected pregnant women in the morning after an overnight fast after an informed consent was obtained. Serum was tested for TSH, free T4, TPO antibodies, using a chemiluminescence immune assay, Thyrocare Technologies Ltd, India with commercially available kits by Novateinbio, USA.
The nonpregnant laboratory reference intervals are taken for TSH $0.3-5.5 \mu \mathrm{IU} / \mathrm{L}$, for TPOAb > $34 \mathrm{IU} / \mathrm{ml}$ consider to be abnormal, free T4 0.7 to $1.8 \mathrm{ng} / \mathrm{dl}$. Based on nonpregnant reference values, euthyroid was defined as normal FT4 and TSH, subclinical hypothyroid was defined as normal FT4 and TSH >5.5 $\mu \mathrm{IU} / \mathrm{L}$, overt hypothyroid defined as FT4 $>1.8 \mathrm{ng} / \mathrm{dl}$ and $\mathrm{TSH}>5.5$ $\mu \mathrm{IU} / \mathrm{L}$.

The trimester-specific reference values for $\mathrm{TSH}$ were $0.1-2.5 \mu \mathrm{IU} / 1,0.2-3.0 \mu \mathrm{IU} / \mathrm{l}$ and $0.3-3.0 \mu \mathrm{IU} / \mathrm{l}$ in the first, second, and third trimesters of pregnancy respectively, considering the recent literature [6,7]. For FT4 0.8-1.8 ng/dl in the first trimester of pregnancy. Based on first trimester-specific reference values euthyroid defined as FT4 and TSH are 0.8-1.8 ng/dl and $0.1-2.5 \mu \mathrm{IU} / \mathrm{ml}$, respectively [6]. All the women having normal FT4 with TSH $>2.5 \mu \mathrm{IU} / \mathrm{ml}$ were diagnosed as subclinical hypothyroid, overt hypothyroid defined as FT4 $<0.8 \mathrm{ng} / \mathrm{dl}$ and TSH $>2.5 \mathrm{mIU} / \mathrm{L}$.

Statistical analysis- Statistical analysis is carried out using Sofa Stats software (Open source statistics, analysis, and reporting software from Paton-Simpson \& Associates Ltd.). Results were presented as mean, standard deviation (SD) for continuous variables; the frequency and percentage were given for qualitative variables. $P$ value and $95 \%$ confidence interval between two different groups, relative risk, the $95 \%$ confidence interval of relative risk and the significance of a difference between two independent proportions were calculated by using medcalc easy to use statistical software bvba, version 16.4.3, Ostend. A p-value of $\leq$ 0.05 was taken as statistically significant.

\section{Results}

The average age of 233 pregnant women enrolled in the study was 22.1 years. The mean of TPO-Ab, TSH and FT4 were $35.95 \mathrm{IU} / \mathrm{ml}, 2.42 \mu \mathrm{IU} / \mathrm{ml}$, and $1.18 \mathrm{ng} / \mathrm{dl}$ respectively (Table 1). 29 (12.4\%) patients were positive for TPOAb, whereas $204(87.6 \%)$ were negative for TPOAb. Mean thyroid hormone values were compared in pregnant women with and without thyroid auto-antibodies. The mean age difference between pregnant women who were TPOAb positive and negative was statistically significant $(23.21 \mathrm{vs} 21.94$ years, $\mathrm{P}=0.03)$. TSH was significantly higher in TPOAb positive women than TPO-Ab negative women (mean $3.15 \mu \mathrm{IU} / \mathrm{ml}$ vs. $2.32 \mu \mathrm{IU} / \mathrm{ml}, \mathrm{p}=0.01$ ). Mean FT4 was not influenced by antibody status with $\mathrm{p}=0.37$ (Table 2 , Fig 1).

Table-1: Thyroid profile of study group.

\begin{tabular}{|c|c|c|c|c|}
\hline Statistics & Age & TPO Ab $(\mathbf{I U} / \mathbf{m l})$ & TSH $(\boldsymbol{\mu I U} / \mathbf{m l})$ & FT4 $(\mathbf{n g} / \mathbf{d l})$ \\
\hline Mean & 22.1 & 35.95 & 2.42 & 1.18 \\
\hline SD & 2.98 & 93.54 & 1.64 & 0.17 \\
\hline Lower limit & 18 & 6 & 0.56 & 0.9 \\
\hline Upper limit & 29 & 372 & 7.61 & 1.49 \\
\hline
\end{tabular}


SD: Standard Deviation; TPOAb: Thyroperoxidase antibodies; TSH: Thyroid Stimulating Hormone; FT 4: Free thyroxine.

Table-2: Comparison of thyroid hormones with autoimmunity.

\begin{tabular}{|c|c|c|c|c|}
\hline Parameters & TPOAb positive & TPOAb negative & $P$ value & $95 \% \mathrm{CI}$ \\
\hline Age (Years) & $23.21 \pm 4.28$ & $21.94 \pm 2.73$ & $0.03 *$ & 0.11 to 2.43 \\
\hline $\mathrm{TSH}(\mu \mathrm{IU} / \mathrm{ml})$ & $3.15 \pm 1.88$ & $2.32 \pm 1.58$ & $0.01 *$ & 0.2 to 1.46 \\
\hline FT 4 (ng/dl) & $1.15 \quad 1.15 \pm 0.14$ & $1.18 \pm 0.17$ & 0.37 & -0.1 to 0.04 \\
\hline
\end{tabular}

TSH: Thyroid Stimulating Hormone; FT 4: Free thyroxine; TPOAb: Thyroperoxidase antibodies; CI: confidential intervals;* Significance

Based on non-pregnant reference intervals, among 233 pregnant women, 221 (94.8\%) were diagnosed as euthyroid, 12 $(5.2 \%)$ were diagnosed as subclinical hypothyroid, none of them were overt hypothyroid. Among 221 euthyroid pregnant women 26 (11.8\%) were TPO-Ab positive and 195 (88.2\%) were TPO-Ab negative. Among 12 subclinical hypothyroid pregnant women 3 (25\%) were TPO-Ab positive and 9 (75\%) were TPO-Ab negative (Table 3 ).

Table-3: Comparison of prevalence of autoimmunity in thyroid subjects based on non pregnant reference intervals

\begin{tabular}{|c|c|c|c|}
\hline Thyroid status & N (\%) & TPOAb positive & TPOAb negative \\
\hline Euthyroid & $221(94.8)$ & $26(11.8)$ & $195(88.2)$ \\
\hline SCH & $12(5.2)$ & $3(25)$ & $9(75)$ \\
\hline Total & $\mathbf{2 3 3}$ & $\mathbf{2 9}(\mathbf{1 2 . 4 )}$ & $\mathbf{2 0 4}(\mathbf{8 7 . 6 )}$ \\
\hline
\end{tabular}

SCH: Subclinical Hypothyroid; TPOAb: Thyroperoxidase antibodies

Based on first trimester-specific reference intervals, among 233 pregnant cases, 156 (66.9\%) were diagnosed as euthyroid, 65 (27.9\%) were diagnosed as subclinical hypothyroid, 7 (3\%) were diagnosed as overt hypothyroid and 5 $(2.1 \%)$ were diagnosed as isolated hypothyroxinemia (IH). Among 156 euthyroid cases, 11 (7\%) were TPO-Ab positive and $145(93 \%)$ were TPO-Ab negative. Among 65 subclinical hypothyroid, 16 (24.6\%) were TPO-Ab positive, 49 (75.4\%) were TPO-Ab negative. Among seven overt hypothyroid, 2 (28.6\%) were TPOAb positive while $5(71.4 \%)$ were TPO-Ab negative. Among five overt hypothyroid, none of them were TPO-Ab positive (Table 4).

Table-4: Comparison of prevalence of autoimmunity in thyroid subjects based on first trimester specific reference intervals

\begin{tabular}{|c|c|c|c|}
\hline Thyroid status & N $(\%)$ & TPOAb positive & TPOAb negative \\
\hline Euthyroid & $156(66.9)$ & $11(7)$ & $145(93)$ \\
\hline SCH & $65(27.9)$ & $16(24.6)$ & $49(74.5)$ \\
\hline OH & $7(3)$ & $2(28.6)$ & $5(71.4)$ \\
\hline IH & $5(2.1)$ & $0(0)$ & $5(100)$ \\
\hline Total & 233 & $29(12.4)$ & $204(87.6)$ \\
\hline
\end{tabular}

SCH: Subclinical Hypothyroid; OH: Overt hypoyhroid; IH Isolated hypothyroxenemia; TPOAb: Thyroperoxidase antibodies

The prevalence of euthyroid was higher than subclinical hypothyroid $(94.8 \%$ vs. $66.9 \%, \mathrm{p}<0.0001)$ when non- pregnant reference intervals were used. The prevalence of subclinical hypothyroid was significantly higher than euthyroid $(27.7 \%$ vs. $5.2 \%, \mathrm{p}<0.0001$ ) when first trimester-specific reference intervals were used. If the non- pregnant laboratory TSH and FT4 reference intervals were applied to our study participants, misclassification of maternal thyroid function would occur. $65(27.9 \%)$ pregnant women with a TSH above the first trimester-specific reference intervals would not have been identified and misclassified as euthyroid. 53(22.7\%) women would have missed diagnosis as subclinical hypothyroidism. 
For FT4, $12(5.2 \%)$ women with low levels, among these $7(3 \%)$ and $5(2.1 \%)$ pregnant women would not have been identified as overt hypothyroidism and isolated hypothyroxinemia (Table 5, Fig 2).

Table-5: Thyroid diagnosis based on non pregnant reference intervals and first trimester specific reference intervals

\begin{tabular}{|c|c|c|c|c|c|}
\hline Thyroid status & $\begin{array}{c}\text { Non pregnant RI } \\
\mathbf{N}(\boldsymbol{\%})\end{array}$ & $\begin{array}{c}\mathbf{1}^{\text {st }} \text { trimester RI } \\
\mathbf{N}(\boldsymbol{\%})\end{array}$ & P value & $\mathbf{9 5 \%} \mathbf{C I}$ & $\begin{array}{c}\text { Results misclassified } \\
\mathbf{N}(\boldsymbol{\%})\end{array}$ \\
\hline Euthyroidism & $221(94.8)$ & $156(66.9)$ & $<0.0001$ & $20.85-34.8$ & $65(27.9)$ \\
\hline SCH & $12(5.2)$ & $65(27.9)$ & $<0.0001$ & $15.93-29.4$ & $53(22.7)$ \\
\hline $\mathrm{OH}$ & $0(0)$ & $7(3)$ & 0.79 & $-1.54-1.6$ & $7(3)$ \\
\hline $\mathrm{IH}$ & $0(0)$ & $5(2.1)$ & 0.83 & $-1.55-1.61$ & $5(2.1)$ \\
\hline
\end{tabular}

SCH: Subclinical Hypothyroid; OH: Overt hypoyhroid; IH Isolated hypothyroxenemia; RI: Reference Intervals; CI: Confidential Intervals.

The incidence of autoimmunity was significantly more in subclinical hypothyroid than euthyroid $(62.1 \%$ vs. $37.9 \%, \mathrm{p}=$ 0.0003, RR 3.66, 95\% CI 1.82-7.34) when first trimester-specific reference intervals were used, whereas the incidence of autoimmunity was not significant when nonpregnant reference intervals were used (Table 6, Fig 3).

Table 6: Prevalence of TPOAb positive pregnant women in thyroid subjects based on non pregnant reference intervals and first trimester specific reference intervals.

\begin{tabular}{|c|c|c|c|c|c|}
\hline $\begin{array}{c}\text { Reference } \\
\text { intervals }\end{array}$ & Euthyroid & $\begin{array}{c}\text { Subclinical } \\
\text { hypothyroid }\end{array}$ & P value & Relative risk & $\begin{array}{c}\text { 95\% Confidential } \\
\text { Intervals }\end{array}$ \\
\hline Non pregnant & $26(89.7)$ & $3(10.3)$ & 0.157 & 2.13 & $0.75-0.04$ \\
\hline $1^{\text {st }}$ trimaster & $11(37.9)$ & $18(62.1)$ & 0.0003 & 3.66 & $1.82-7.34$ \\
\hline
\end{tabular}

\section{Discussion}

Maternal thyroid dysfunction is of greater importance for the fetus during the first trimester of pregnancy. Pregnancy has profound effects on the regulation of thyroid function in healthy women and patients with thyroid disorders. These effects need to be recognized, precisely assessed, clearly interpreted, and correctly managed. Subclinical thyroid dysfunction is probably more prevalent and frequently remains undiagnosed unless specific screening programs are initiated to disclose thyroid function abnormalities in early gestation. Maternal hypothyroidism is associated with various maternal and fetal adverse outcomes; hence, there is a need for screening subclinical hypothyroidism and thyroid autoimmunity in pregnancy, especially in the first trimester when the fetal thyroid tissue is not functional. The role of routine screening becomes all the more relevant in these patients as they are asymptomatic.

Dosiou et al [8] reported that screening pregnant women for TSH in the first trimester of pregnancy is cost saving compared with no screening and screening using anti-TPOAb was also economically favorable. TSH advocated as the initial screening test because
TSH is a more sensitive marker of thyroid status than FT4. FT4 (and FT3) is responsible for thyroid hormone action and that maternal hypothyroxinemia (normal TSH but low FT4) is associated with the neuropsychological deficit in the offspring [9]. According to the recommendations made by the National Academy of Clinical Biochemistry (NACB) of the United States, TPOAb should also be measured: $\mathrm{TPOAb}$ is the most sensitive test for detecting autoimmune thyroid disease, is typically the first abnormality to appear in the course of developing hypothyroidism secondary to Hashimoto's thyroiditis. The appearance of TPOAb usually precedes the development of thyroid dysfunction [10].

According to the American Thyroid Association, 10 to $20 \%$ of all pregnant women in the first trimester of pregnancy are positive for Hashimoto's antibodies, but they are euthyroid [7]. In our study, $12.4 \%$ of pregnant women were positive for TPOAb, comparable with Ratan Chandra et al 2016 study [11] reported, 12.15\% were TPO Ab positive, but higher than Sieiro Netto et al study [12] reported, 5.4\% were thyroid autoantibody positive. 
Kontiainen et al [13] found an increase in the titer of TPOAbs with age, but this correlation was not statistically significant. In our study there was a significant increase in TPOAbs with age. The mean serum TSH values were significantly higher in thyroid autoantibody-positive women compared to women with negative thyroid autoantibodies.

National Association of Clinical Biochemistry has stated that it is likely that in future the upper limit of the euthyroid reference range of serum TSH will be reduced to $2.5 \mu \mathrm{IU} / \mathrm{ml}$ from $4.5 \mu \mathrm{IU} / \mathrm{ml}$ for all adults, because more than $95 \%$ of normal euthyroid volunteers have serum TSH values between 0.4 and $2.5 \mu \mathrm{IU} / \mathrm{ml}$ [14].

The American Association of Clinical Endocrinologists has continued to recommend $4.5 \mu \mathrm{IU} / \mathrm{ml}$ as the upper limit of normal TSH value, although some individuals within the range of 2.6-4.5 $\mu \mathrm{IU} / \mathrm{ml}$ may have subclinical thyroid disease, there is a lack of evidence of adverse outcome in this group [15]. However, American Thyroid Association Guidelines (2011) recommends 2.5 $\mu \mathrm{IU} / \mathrm{ml}$ as the upper limit of TSH in the first trimester of pregnancy [7]. Recent Endocrine Society guidelines also suggested $0.1-2.5 \mu \mathrm{IU} / \mathrm{ml}$ as the "normal" range for TSH values in the first trimester and $<3 \mu \mathrm{IU} / \mathrm{ml}$ in the second and third trimester [16].

Our study used two different series of reference intervals as per the American Thyroid Association (ATA) Guidelines (2011) and Recent Endocrine Society guideline's recommendations, first trimester-specific reference intervals and nonpregnant reference intervals, to identify the prevalence of misdiagnosed thyroid disorders in first trimester pregnancy. As per the ATA guidelines for first trimester-specific reference intervals, in our study, the prevalence of euthyroid was $66.9 \%$ and among them, 7\% were TPOAb positive. Ratan Chandra et al 2016 study [11] reported that $1.47 \%$ had TPO-Ab positive euthyroid women. This subgroup of the population is at increased risk of developing hypothyroidism and should be monitored every 4-6 weeks.

The prevalence of subclinical hypothyroid was $27.9 \%$ and among them, $24.6 \%$ were TPO-Ab positive, which is much higher than other studies [17-19] in which the prevalence is $2.8 \%, 10.9 \%$, and $13.8 \%$, because the cutoff value of TSH $>2.5 \mu \mathrm{IU} / \mathrm{ml}$ used to classify thyroid status, but comparable to the Ratan Chandra et al 2016 study [11] reported $32.9 \%$ of SCH. The prevalence of overt hypothyroid was $3 \%$ and among them, $28.6 \%$ were TPO- Ab positive, which is higher than Klein RZ et al [20] study reported $0.3-0.5 \%$ in West, whereas the prevalence isolated hypothyroxenemia was $2 \%$ and none of them were TPOAb positive.

The prevalence of subclinical hypothyroid was significantly higher than euthyroid as per the ATA guidelines for first trimester-specific reference intervals were used rather than nonpregnant reference intervals. 27.9\% pregnant women with a TSH above the first trimester-specific reference intervals would not have been identified and misclassified as euthyroid if nonpregnant references were used. Wang W et al (2011) [9] found that 2\% patients with subclinical hypothyroidism would be misclassified if nonpregnant reference intervals were used. Stricker et al [1] reported that $3.6 \%$ of patients with elevated TSH would be missed \& $3.7 \%$ of patients with low TSH would be misdiagnosed by using the nonpregnant reference intervals to diagnose thyroid diseases. In our study higher prevalence of missed diagnosis occurred, $22.7 \%$ of subclinical hypothyroid, $3 \%$ of overt hypothyroid, $2.1 \%$ of isolated hypothyroxinemia would be missed if nonpregnant reference intervals were used. Vaidya et al [21] concluded that the prevalence of hypothyroxinemia increased to $3.7 \%$ when first trimester-specific reference intervals were used rather than the general population reference intervals.

Stricker et al study [1] reported that the relative risk of thyroid autoimmunity was 4.6-fold more frequently in hypothyroid pregnant women with $\mathrm{TSH}>3 \mu \mathrm{IU} / \mathrm{l}$, compared with euthyroid controls. In our study, the relative risk of thyroid autoimmunity was 3.66 times in subclinical hypothyroid pregnant women with TSH more than $2.5 \mu \mathrm{IU} / \mathrm{l}$ than euthyroid pregnant women with $\mathrm{p}=0.0003$, when first trimester-specific reference intervals were used.

Although the relative risk of autoimmunity was 2.13 times in subclinical hypothyroid than euthyroid pregnant women, but not significant when nonpregnant reference intervals were used. This may reflect lower thyroidal reserve during pregnancy when a greater amount of thyroid hormones is demanded.

Brent [22] reported that the potential adverse outcomes are so significant and the tools to diagnose and treat thyroid disease are easily accessible, that it is no longer acceptable for even 1/3 rd of pregnant women to remain undiagnosed. Even a small percentage of thyroid 
disorders in early pregnancy should not be missed. So in our country we must follow Indian Thyroid Society Guidelines which clearly recommend that "all pregnant women should be screened at the first antenatal visit by measuring TSH levels", and highlight that ideally screening should be carried out during pre-pregnancy evaluation or as soon as pregnancy is confirmed. As our data show, utilization of non-pregnant reference intervals to interpret thyroid function tests in pregnant women has the potential to result in a large number of misclassified results, and could contribute to suboptimal patient care. Therefore, our results support assessing TSH, FT4, and TPOAb as the initial screening tests for thyroid dysfunction in early pregnancy, using pregnancy-specific reference intervals. The early and appropriate detection of thyroid dysfunction and timely interventions that improve maternal-fetal prognosis require reliable pregnancy specific reference intervals of the thyroid hormones. Establishing trimester-specific reference intervals in each population is essential for accurate assessment of thyroid function [23].

\section{Conclusion}

The trimester-specific reference interval for TSH differs from the non-pregnant reference intervals that can lead to misdiagnosis of subclinical hypothyroidism and overt hypothyroidism. Our study confirms that $22.7 \%$ of subclinical hypothyroid, $3 \%$ of overt hypothyroid, $2.1 \%$ of isolated hypothyroxinemia would be missed if non pregnant reference intervals were used.

All pregnant women should be screened at the first antenatal visit by measuring TSH, FT4, and TPOAb levels using pregnancy-specific reference intervals.

These trimester-specific reference intervals are essential in everyday clinical practice for the correct interpretation of thyroid hormone values and accurate classification of thyroid disorders and to evaluate the risk for both obstetric complications and impaired fetal development.

Acknowledgement- I would like to thank professor \& HOD of Biochemistry and Gynecology \& Obstetrics department, Govt Maternity Hospital and the staff for their cooperation during the collection of blood samples.

Funding: Nil, Conflict of interest: None initiated,

Permission from IRB: Yes

Figures:

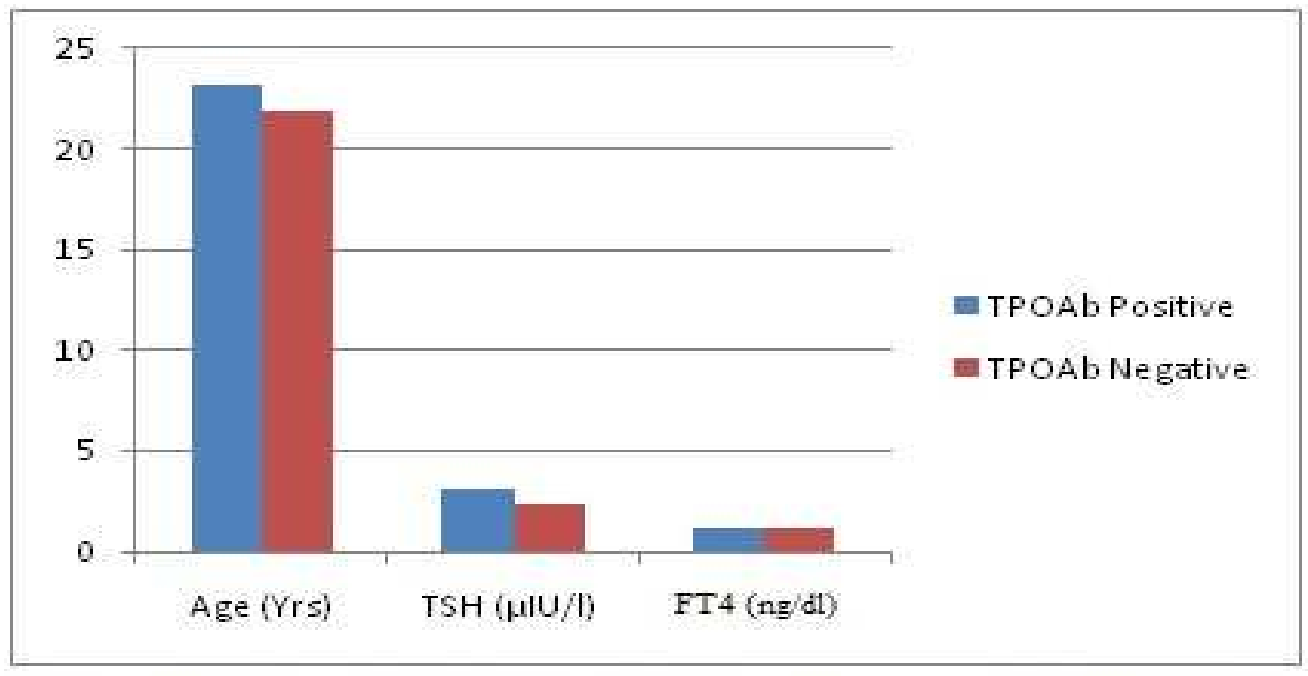

TSH: Thyroid Stimulating Hormone; FT 4: Free thyroxine; TPOAb: Thyroperoxidase antibody.

Fig 1: Comparison of thyroid hormones with autoimmunity 


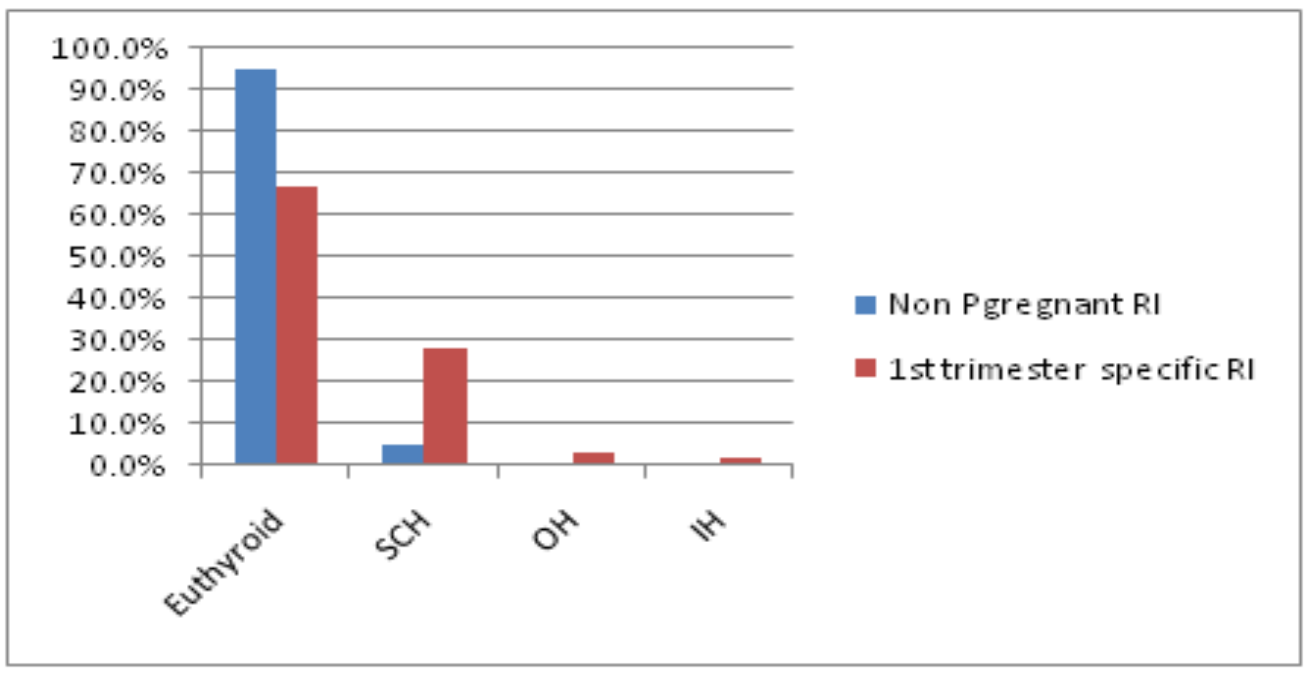

$\mathrm{SCH}$ : Subclinical Hypothyroid; OH: Overt hypoyhroid; IH Isolated hypothyroxenemia; RI: Reference Interval.

Fig 2: Thyroid diagnosis based on non pregnant reference intervals and first trimester specific reference intervals

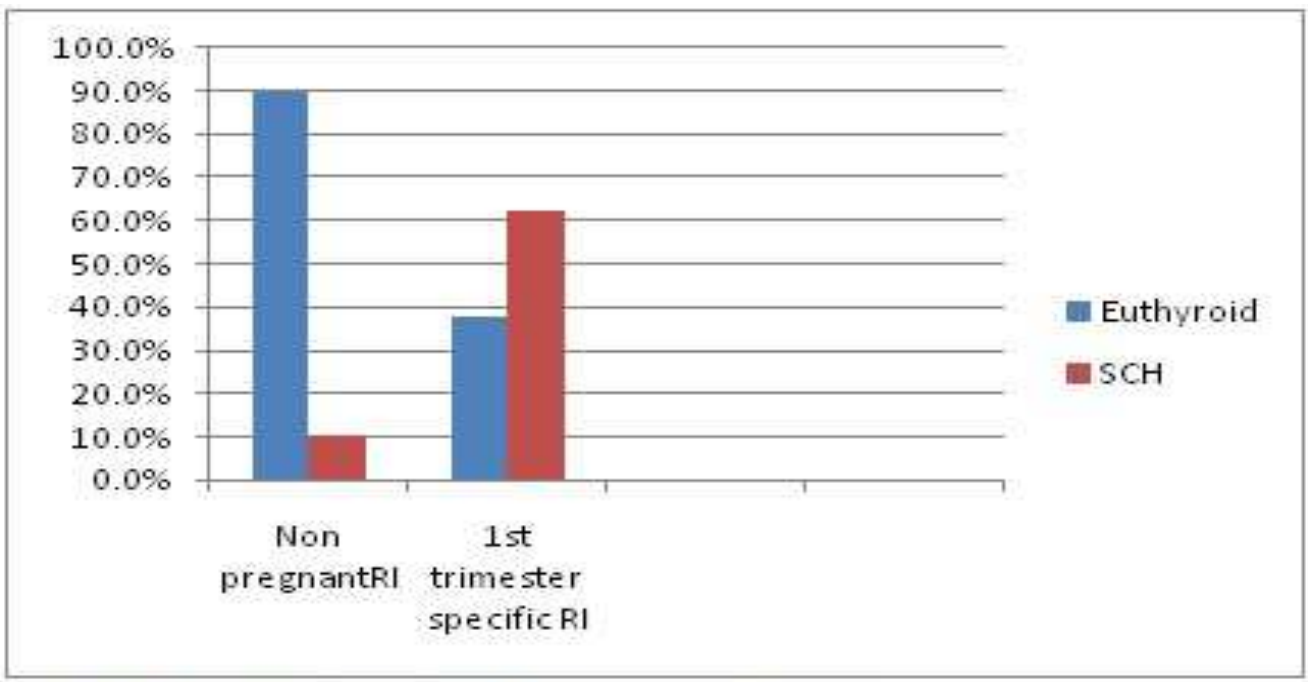

SCH: Subclinical hypothyroid; RI: Reference Interval.

Fig 3: Prevalence of TPOAb positive pregnant women in thyroid subjects based on non pregnant reference intervals and first trimester specific reference intervals

\section{References}

1. Strecker RT, Echenard M, Eberhart R. Chevailler MC, Perez V, Quinn F A et al. Evaluation of maternal thyroid function in pregnancy: the importance of using gestational age - specific reference intervals. European Journal of Endocrinology. 2007; 157:509- 514. (doi: 10. 1530/EJE-07-0249.
2. Haddow JE, Palomaki GE, Allan WC, Williams JR, Knight GJ, Gagnon J, et al. Maternal thyroid deficiency during pregnancy and subsequent neuropsychological development of the child. N Engl J Med. 1999 Aug; 341(8):549-55. 
3. Pop VJ, Brouwers EP, Vader HL, Vulsma T, van Baar AL, de Vijlder JJ. Maternal hypothyroxinaemia during early pregnancy and subsequent child development: a 3-year follow-up study. Clin Endocrinol (Oxf). 2003 Sep; 59(3): 282-288.

4. Stagnaro-Green A, Chen X, Bogden JD, Davies TF, Scholl TO. The thyroid and pregnancy: a novel risk factor for very preterm delivery. Thyroid. 2005 Apr; 15(4): 351-357.

5. Bussen S, Steck T, Dietl J. Increased prevalence of thyroid antibodies in euthyroid women with a history of recurrent in-vitro fertilization failure. Hum Reprod. 2000Mar; 15(3): 545-8.

6. De Groot L, Abalovich M, Alexander EK, Amino $\mathrm{N}$, Barbour L, Cobin RH, et al. Management of thyroid dysfunction during pregnancy and postpartum:an Endoc rine Society clinical practice guideline. J Clin Endocrinol Metab. 2012 Aug; 97(8):2543-65. doi: 10. 1210/jc.2011-2803.

7. Stagnaro-Green A, Abalovich M, Alexander E, Azizi F, Mestman J, Negro R, et al. Guidelines of the American Thyroid Association for the Diagnosis and Management of Thyroid Disease During Pregnancy and Postpartum. Thyroid. 2011 Oct; 21(10):1081-25. doi: 10.1089/thy.2011.0087. Epub. 2011 Jul 25.

8. Dosiou C, Sanders GD, Araki SS \& Crapo LM. Screening pregnant women for autoimmune thyroid disease: a cost-effectiveness analysis. European Journal of Endocrinology. 2008; 158 : 841-851. (doi:10. 1530/ EJE-07-0882)

9. Wang $\mathrm{W}^{1}$, Teng W, Shan Z, Wang S, Li J, Zhu L et al. The prevalence of thyroid disorders during early pregnancy in China: the benefits ofuniversal screening in the first trimester of pregnancy. Eur $\mathrm{J}$ Endocrinol. 2011 Feb; 164(2):263-8. doi: 10.1530/EJE-10-0660. Epub 2010 Nov 8.

10. Leslie D, Lipsky P, Notkins AL. Autoantibodies as predictors of disease. J Clin Invest. 2001 Nov; 108 (10):1417-22.

11. Ratan Chandra Mandal, Debasish Bhar, Anjan Das, Sandip Roy Basunia, Sudeshna Bhar Kundu, Chinmay Mahapatra. Subclinical hypothyroidism in pregnancy: An emerging problem in Southern West Bengal: A cross-sectional study.J Nat ScBiolMed.2016;7(1):80-84.
12. Sieiro Netto L, Medina Coeli C, Micmacher E, Mamede Da Costa S, Nazar L, Galvão D et al. Influence of thyroid autoimmunity and maternal age on the risk of miscarriage. Am J Reprod Immunol. 2004 Nov; 52(5): 312-652: 312-316.

13. Kontiainen S, Melamies L, Miettinen A, Weber T. Thyroid autoantibodies in serum samples with abnormal TSH levels. APMIS. 1994 Sep; 102(9):716-20.

14. Baloch Z, Carayon P, Conte-Devolx B, Demers LM, Feldt-Rasmussen U, Henry JF, et al. Laboratory medicine practice guidelines. Laboratory support for the diagnosis and monitoring of thyroid disease. Thyroid 2003; 13:3-126.

15. Surks MI, Ortiz E, Daniels GH, Sawin CT, Col NF, Cobin RH, et al. Subclinical thyroid disease: Scientific review and guidelines for diagnosis and management. JAMA. 2004; 291:228-38.

16. Negro R, Schwartz A, Gismondi R, Tinelli A, Mangieri T, Stagnaro-Green A. Increased pregnancy loss rate in thyroid antibody negative women with TSH levels between 2.5 and 5.0 in the first trimester of pregnancy. J Clin Endocrinol Metab. 2010; 95:E44-8.

17. Gayathri R, Lavanya S, Raghavan K. Subclinical hypothyroidism and autoimmune thyroiditis in pregnancy - A study in south Indian subjects. J Assoc Physicians India. 2009; 57:691-3.

18. Aggarwal N, Suri V, Joshi B, Dutta P, Bhanshali A, Mukhopadhyay K. Prevalence and impact of subclinical hypothyroidism on pregnancy - Prospective study from apex institute of North India. Indian J Appl Res. 2014; 4:404-6.

19. Dhanwal DK, Prasad S, Agarwal AK, Dixit V, Banerjee AK. High prevalence of subclinical hypothyroidism during first trimester of pregnancy in North India. Indian J Endocrinol Metab. 2013;17:281-4.

20. Klein RZ, Haddow JE, Faix JD, Brown RS, Hermos RJ, Pulkkinen A et al. Prevalence of thyroid deficiency in pregnant women. Clin Endocrinol (Oxf). 1991 Jul; 35(1):41-6.

21. Vaidya B, Anthony S,Bilous M, Shields B,Drury J,Hutchinson S \& Bilous R. Detection of thyroid dysfunction in early pregnancy: Universal screening or targeted high risk case finding. Journal of Clinical 
Endocrinology and Metabolism. 2007; 92: 203-207 (doi: 10. 1210/jc. 2006-1748).

22. Brent GA. Diagnosing thyroid dysfunction in pregnant women:is case finding enough? Journal of Clinical Endocrinology and Metabolism. 2007; 92:3941. (doi:10.1210/jc .2006-2461).
23. Jinfang Xing, Enwu Yuan, Jing Li, Yuchao Zhang, Xiangying Meng, Xia Zhang et al. Trimesterand Assay-Specific Thyroid Reference Intervals for Pregnant Women in China. International Journal of Endocrinology. 2016, Article ID 3754213, 5pp.http: //dx.doi.org/10.1155/2016/3754213.

\section{How to cite this article?}

Kumari BA, Vanumu C. S, Divyasai V. Detection of misdiagnosed thyroid dysfunction in early pregnancy: using nonpregnant and pregnancy specific reference intervals. Int J Med Res Rev 2016;4 (7):12671275.doi:10.17511/ijmrr.2016.i07.33. 